\title{
Aggregate Moisture Content and Fresh Property Control Measures in Cementitious Mortars
}

\author{
Morgan C. Jenkins ${ }^{1}$ and Alexander S. Brand ${ }^{1}$ \\ ${ }^{1}$ Charles E. Via, Jr. Department of Civil and Environmental Engineering, Virginia Tech \\ 750 Drillfield Drive, Blacksburg, VA, USA, 24061 \\ morganj17@vt.edu; asbrand@vt.edu
}

\begin{abstract}
A primary objective for any concrete, or other cementitious composite, is to ensure consistent, reliable, and predictable fresh properties between subsequent batches. This is especially important for additive manufacturing, grouting, and pumping applications, where regulation of the fresh properties is paramount to providing quality control. This study considered the main influences of aggregate moisture content and how that moisture is accounted for during batching on the flow, setting time, and compressive strength of a mortar currently used in an additive manufacturing process. The results indicated that aggregate moisture content can drastically alter the variability in these properties. When fresh properties need to be controlled for a mortar, it is recommended that the aggregates should be saturated surface dry, or at least partially saturated, and that the moisture should be properly accounted for by adjusting the batching proportions. This recommendation is based on the results in this study with the lowest amount of variability and therefore the greatest amount of reliability and consistency.
\end{abstract}

Keywords: mortar, aggregate, workability, setting properties, moisture content, mortar flow

\section{Introduction}

This investigation was initiated when the researchers and their colleagues noted significant quality control issues in the printability of an additive-manufactured mortar between replicate mixes. It was discovered that, while the same mixture proportions were specified, the aggregate moisture condition was not necessarily well-controlled between subsequent batches. This short study examines the effect of aggregate moisture condition and how it is accounted for on the fresh properties of mortars. The results directly impact any construction scenario where strict control of fresh properties is needed, such as additive manufacturing, grouts for tendons in prestressed concrete, pumpable mortars, repair materials, etc.

While the field of additive-manufactured cementitious composites (AMCC) continues to grow and advance at a seemingly exponential rate, a number of materials research needs and requirements have been identified [1], [2]. For instance, quality control measures are needed to produce consistent workability such that the additive-manufactured component can be constructed with reliability according to the intended design specifications. Conventional concrete workability tests, such as slump, are not particularly applicable to AMCC [3], [4], as the rheological property requirements are very different for AMCC compared to conventional cast concrete.

The novelty of the present study is to consider the effect of aggregate moisture content on an AMCC mixture in order to evaluate what quality control measures may be required to ensure consistency and reliability for fresh properties. Indeed, previous studies have demonstrated that the aggregate moisture content can affect the fresh and hardened properties of mortars and concrete [5]-[8], particularly for aggregates with high absorption capacities [9]-[15]. In particular, the effect of aggregate or surface moisture content (e.g., dry, partially saturated, saturated surface dry, over saturated, etc.) has been shown to significantly influence the microstructure development [9], [11], [14], [16], [17]. In terms of fresh properties, the aggregate moisture content and how it is accounted for during batching can affect initial workability and the rate of workability loss [6], [10], [13], [18], [19]. In general, oven dry conditions appear to negatively impact fresh and hardened properties more than partially to fully saturated conditions. Since aggregate moisture content and how it is accounted for during batching has been demonstrated to measurably affect the workability of concrete and other cementitious composites, the objective of this study is to observe how the aggregate moisture content and how it is accounted for will influence mortar flow, setting time, and compressive strength. 


\section{Experimental Methodology}

Two different fine aggregates were evaluated: a natural sand and a manufactured sand. The gradation per ASTM C136-19 is shown in Figure 1. The bulk specific gravity, apparent specific gravity, and absorption per ASTM C128-15 are shown in Figure 1. The aggregates were prepared in three moisture conditions: oven dry (OD), saturated surface dry (SSD), and air dry (AD). The OD condition was prepared by heating the aggregate at $105^{\circ} \mathrm{C}$ for at least 12 hours. The SSD condition was prepared by mixing OD aggregates with the exact amount of water to achieve SSD conditions (i.e., according to the absorption capacity) and storing the mixture in a sealed container for several hours. The AD condition was simply the stockpile moisture condition in the ambient laboratory environment.

A total of 12 mortars were prepared in a factorial analysis of aggregate type (2), moisture condition (3), and mixture batching (2), as shown in Table 1. Two different batching approaches were considered: Group 1 tests mixed the aggregates "asis" without adjusting the proportioning according to the aggregate moisture content whereas Group 2 tests did properly adjust batching proportions.

Although the Group 1 batching does not follow conventional proportioning methodology, the objective was to observe how not accounting for aggregate moisture can significantly affect properties, based on previous work by the authors [9]. The Group 2 batching does follow conventional proportioning methodology as it does account for the aggregate moisture content, which can significantly influence the fresh and hardened properties, as shown in previous work by the authors [10] and by a number of articles cited in the Introduction.

The mortar mix design followed a formulation that has been identified to yield AMCC of suitable printability [20]. The mixture has a design water-to-cementitious $(\mathrm{w} / \mathrm{cm})$ ratio of 0.375 by weight and a sand-to-cementitious $(\mathrm{s} / \mathrm{cm}) \mathrm{ratio}$ of 1.5 by weight. The total cementitious content was composed by weight of $60 \%$ Type III portland cement, $30 \%$ ground granulated blast furnace slag, and 10\% silica fume. A high range water reducing admixture was also added at a dosage rate of $540 \mathrm{~mL}$ per $100 \mathrm{~kg}$ cementitious. All mortars were mixed per ASTM C305-14.

The fresh and early hardened properties of these mortars were evaluated, specifically mortar flow, setting time, and 1day compressive strength. The mortar flow was determined per ASTM C1437-15 as soon as the mortar was mixed. The setting time was measured per ASTM C807-18, except that the mortar surface was sealed with plastic between each subsequent measurement. Penetration measurements for setting time were collected approximately every 15 minutes and then were collected every 5 minutes as the mortar approached final set. The average 1-day compressive strength was determined from three $50 \mathrm{~mm}$ cube specimens per ASTM C109-20. The cube specimens were cast and sealed with plastic to be cured at ambient laboratory conditions prior to testing after 1 day of curing. 
3. Results and Discussion 3.1. Mortar Flow

The mortar flow, defined per ASTM C1437-15 as the percent increase from the base diameter, is shown in Table 2. Interestingly, the average for each sand type did not significantly change between the results for Groups 1 and 2. Overall, the manufactured sand had less variability than the natural sand and demonstrated greater flow increases than the natural sand in all cases (Table 3). This was likely due to absorption content (i.e., $0.47 \%$ for manufactured sand and $1.08 \%$ for natural sand) as well as differences in gradation, fineness, and particle shape between the two fine aggregates. Because the manufactured sand had a lower absorption capacity, the potential for variation in the flow was likely reduced. This is highlighted in the fact that the standard deviations for the manufactured sand were $3 \%$ and $4 \%$ for Groups 1 and 2, respectively, while the standard deviation for the natural sand were $9 \%$ and $6 \%$ for Groups 1 and 2, respectively.

Based on the results in Tables 2, 3, and 4, aggregates with low absorption capacity, such as the manufactured sand at $0.47 \%$, may not greatly affect workability regardless of the aggregate moisture content or if the aggregate moisture content is accounted for during batching. However, the results for natural sand, with an absorption capacity of $1.08 \%$, appears to show greater influence on workability. For Group 1, the trend agrees with the expected

\begin{tabular}{llccc}
\hline $\begin{array}{l}\text { Batching } \\
\text { Group }\end{array}$ & Aggregate Type & $\begin{array}{c}\text { Average } \\
(\mathbf{\%})\end{array}$ & $\begin{array}{c}\text { Standard } \\
\text { Deviation (\%) }\end{array}$ & $\begin{array}{c}\text { Range } \\
(\boldsymbol{\%})\end{array}$ \\
\hline \multirow{2}{*}{ Group 1 } & Natural Sand & 55 & 9 & 42 \\
& $\begin{array}{l}\text { Manufactured } \\
\text { Sand }\end{array}$ & 79 & 3 & 9 \\
\hline \multirow{2}{*}{ Group 2 } & Natural Sand & 55 & 6 & 25 \\
& $\begin{array}{l}\text { Manufactured } \\
\text { Sand }\end{array}$ & 77 & 4 & 12 \\
\hline
\end{tabular}

Table 4. Flow Results Irrespective of Aggregate Type or Batching Group

\begin{tabular}{lccc}
\hline $\begin{array}{l}\text { Aggregate } \\
\text { Condition }\end{array}$ & $\begin{array}{c}\text { Average } \\
(\boldsymbol{\%})\end{array}$ & $\begin{array}{c}\text { Standard } \\
\text { Deviation }(\boldsymbol{\%})\end{array}$ & $\begin{array}{c}\text { Range } \\
(\boldsymbol{\%})\end{array}$ \\
\hline OD & 65 & 14 & 57 \\
AD & 62 & 13 & 45 \\
SSD & 72 & 10 & 34 \\
\hline
\end{tabular}
behaviour in that OD reduced the flow the most while SSD yielded the greatest flow. Similar behaviour has been reported, such as in the form of workability loss [13], [19], and is attributed to the OD aggregate quickly absorbing water from the paste and affecting the local w/c ratio. This behaviour is not as drastic in Group 2, since additional water is batched for the OD aggregate, locally increasing the w/c ratio and counteracting the workability reduction due to the OD aggregate, which has also been demonstrated in other studies (e.g., [6], [10], [18]).

When comparing the flow results for the 12 different mortars, the moisture condition was investigated to determine which performed the most consistently between the different aggregate types (Table 4). Regardless of the aggregate type or the batching group, the OD condition yielded the greatest variability while the SSD condition yielded the least amount of variability. This would preliminarily suggest that an SSD condition can result in a mix with more consistent workability irrespective of aggregate type or how aggregate moisture is accounted in batching. However, it is possible that all of the mixtures exhibited suitable flow for production of AMCC, as Tay et al. [21] recommended mortar flow values of 50\% to $90 \%$ for suitable printability via extrusion.

\subsection{Setting Time}


The setting time was determined using a manual Vicat needle apparatus according to ASTM C807-18, the results of which are shown in Table 5. Similar to the flow results, the setting time standard deviation and range were greater for Group 1 than for Group 2 (Table 5). This is also likely to be a result of the absorption capacity and how the water is accounted for during the batching procedure, as previously

Table 5. Setting Time Results Irrespective of Moisture Condition

\begin{tabular}{|c|c|c|c|c|}
\hline $\begin{array}{l}\text { Batching } \\
\text { Group }\end{array}$ & Aggregate Type & $\begin{array}{c}\text { Average } \\
\text { (min) }\end{array}$ & $\begin{array}{c}\text { Standard } \\
\text { Deviation }(\mathrm{min}) \\
\end{array}$ & Range $(\%)$ \\
\hline \multirow[b]{2}{*}{ Group 1} & \multirow{2}{*}{$\begin{array}{l}\text { Natural Sand } \\
\text { Manufactured } \\
\text { Sand }\end{array}$} & 166 & 24 & 33 \\
\hline & & 160 & 31 & 47 \\
\hline \multirow[b]{2}{*}{ Group 2} & \multirow{2}{*}{$\begin{array}{l}\text { Natural Sand } \\
\text { Manufactured } \\
\text { Sand }\end{array}$} & 180 & 8 & 11 \\
\hline & & 184 & 9 & 11 \\
\hline
\end{tabular}
discussed. Furthermore, Table 5 demonstrates that the setting time was not significantly influenced by the aggregate type, unlike the flow results.

Also similar to the flow results is the effect of aggregate condition regardless of the aggregate type or the batching group. Table 6 shows a clear trend of increasing setting time: $\mathrm{OD}<\mathrm{AD}<$ SSD. This same trend was also demonstrated by Cortas et al. [7] and similar trends can be inferred from the Vicat penetration tests

Table 6. Setting Time Results Irrespective of Aggregate Type or Batching Group

\begin{tabular}{lccc}
\hline $\begin{array}{c}\text { Aggregate } \\
\text { Condition }\end{array}$ & $\begin{array}{c}\text { Average } \\
(\mathbf{m i n})\end{array}$ & $\begin{array}{c}\text { Standard } \\
\text { Deviation }(\mathbf{m i n})\end{array}$ & $\begin{array}{c}\text { Range } \\
(\mathbf{\%})\end{array}$ \\
\hline OD & 156 & 26 & 44 \\
AD & 169 & 14 & 23 \\
SSD & 192 & 6 & 8 \\
\hline
\end{tabular}
by Ortiz et al. [5]. This trend is directly relatable to the flow results and the workability loss (e.g., [13], [19]) reported in the literature for OD aggregates. The OD aggregates will absorb moisture from the surrounding cement paste, locally reducing the effective w/c ratio and accelerating set. Indeed, a general trend is reported in the literature that setting time decreases as w/c ratio decreases (e.g., [22]-[25]).

For both groups, the SSD fine aggregate performed the most consistently with the lowest standard deviation and range in setting times (Table 6); this behaviour is expected because a fine aggregate at SSD should neither give nor take moisture from the cement paste. Thus, cement hydration, as indicated by setting time, may not be influenced by the fine aggregate types in this study when the aggregate is in SSD condition.
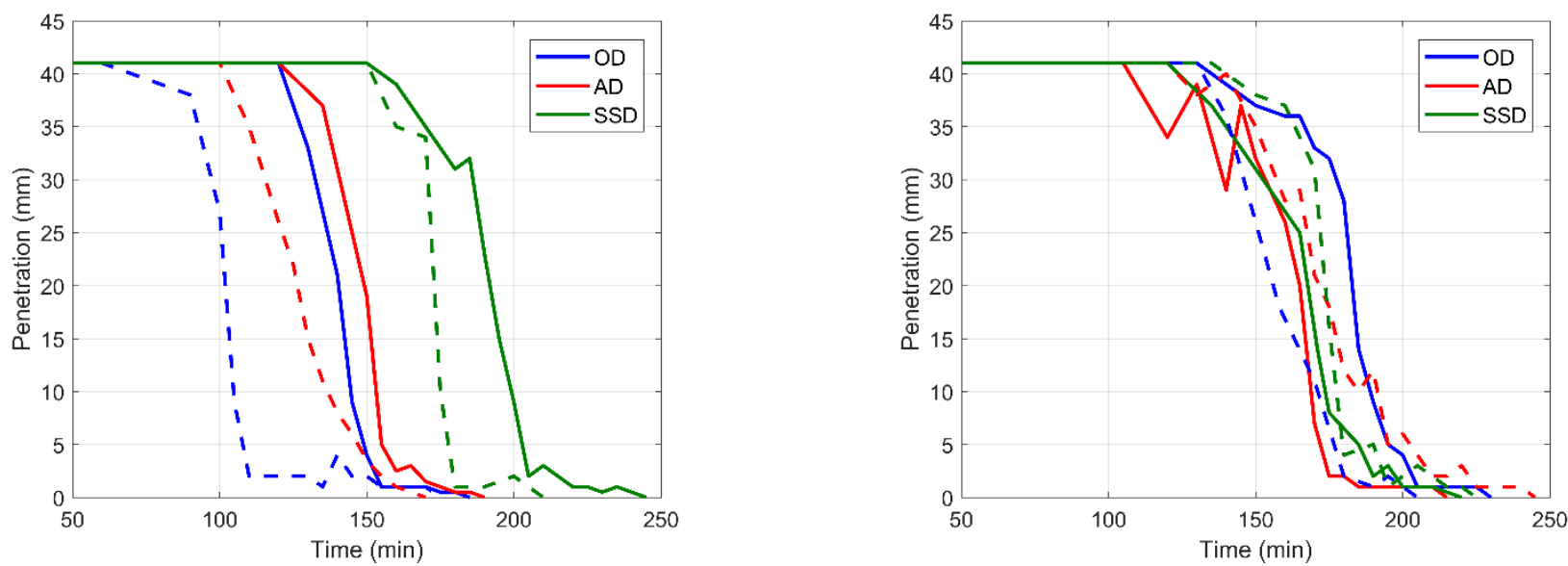

Figure 2. Setting time data for Group 1 (left) and Group 2 (right) as a function of aggregate type - natural sand (solid lines) and manufactured sand (dashed lines) - and aggregate moisture condition.

Figure 2 shows the time-dependent Vicat penetration readings for setting time. It is evident how properly adjusting for the aggregate moisture condition in Group 2 results in a narrow band of setting behaviour as opposed to not accounting for 
aggregate moisture in Group 1. The trends in Figure 2 reiterate the importance of accounting for aggregate moisture during batching to ensure improved consistency in the behaviour.

Based on these data, it is evident that the most consistent and reliable mixtures, in terms of setting time, would include SSD aggregates and the Group 2 batching (i.e., account for the moisture condition). It should also be noted that the time at which the mixture no longer produces layers of suitable quality and the time at which the extrusion nozzle gets blocked by hydrating cement can occur hours before initial set [26]. Therefore, in terms of quality control measures to produce a mix with a consistent and, more importantly, with a predictable setting time, it is recommended that SSD aggregates and the Group 2 batching be used.

\subsection{Compressive Strength}

The 1-day compressive strength results and statistics are shown in Table 7. The manufactured sand obtained a slightly higher compressive strength for both groups (Table 8), indicating that fine aggregate type had a slight influence on performance. This is likely due to the particle shape and gradation of Table 7. 1-Day Compressive Strength Results

\begin{tabular}{|c|c|c|c|c|c|c|}
\hline $\begin{array}{l}\text { Batching } \\
\text { Group }\end{array}$ & $\begin{array}{l}\text { Aggregate } \\
\text { Type }\end{array}$ & $\begin{array}{l}\text { Aggregate } \\
\text { Condition }\end{array}$ & $\begin{array}{l}\text { Mortar } \\
\text { No. }\end{array}$ & $\begin{array}{c}\text { Average } \\
\text { (MPa) }\end{array}$ & $\begin{array}{c}\text { Standard } \\
\text { Deviation } \\
\text { (MPa) }\end{array}$ & $\begin{array}{c}\text { Range } \\
(\%)\end{array}$ \\
\hline \multirow{6}{*}{ Group 1} & \multirow{3}{*}{ Natural Sand } & OD & 1 & 19.6 & 1.5 & 14.9 \\
\hline & & $\mathrm{AD}$ & 2 & 21.0 & 0.2 & 1.5 \\
\hline & & SSD & 3 & 14.8 & 0.5 & 5.7 \\
\hline & \multirow{3}{*}{$\begin{array}{l}\text { Manufactured } \\
\text { Sand }\end{array}$} & OD & 4 & 17.1 & 0.5 & 5.5 \\
\hline & & $\mathrm{AD}$ & 5 & 25.4 & 1.8 & 13.8 \\
\hline & & SSD & 6 & 16.7 & 0.5 & 5.5 \\
\hline \multirow{6}{*}{ Group 2} & \multirow{3}{*}{ Natural Sand } & OD & 7 & 16.6 & 0.1 & 1.6 \\
\hline & & $\mathrm{AD}$ & 8 & 19.5 & 0.3 & 2.8 \\
\hline & & SSD & 9 & 17.7 & 0.6 & 6.3 \\
\hline & \multirow{3}{*}{$\begin{array}{l}\text { Manufactured } \\
\text { Sand }\end{array}$} & OD & 10 & 19.0 & 0.3 & 3.2 \\
\hline & & $\mathrm{AD}$ & 11 & 21.2 & 0.5 & 4.2 \\
\hline & & SSD & 12 & 17.5 & 0.1 & 1.2 \\
\hline
\end{tabular}
manufactured sand. The manufactured sand is a crushed stone, resulting in greater angularity in the particle shape. In contrast, the natural sand is less angular and has a rounder, smoother particle shape. Therefore, the roughness of the manufactured sand

Table 9. 1-Day Compressive Strength Results Irrespective of Aggregate Type or Batching Group

\begin{tabular}{lccc}
\hline $\begin{array}{l}\text { Aggregate } \\
\text { Condition }\end{array}$ & $\begin{array}{c}\text { Average } \\
(\mathbf{M P a})\end{array}$ & $\begin{array}{c}\text { Standard } \\
\text { Deviation } \\
(\mathbf{M P a})\end{array}$ & $\begin{array}{c}\text { Range } \\
(\boldsymbol{\%})\end{array}$ \\
\hline OD & 18.1 & 1.4 & 26 \\
AD & 21.8 & 2.3 & 37 \\
SSD & 16.7 & 1.2 & 23 \\
\hline
\end{tabular}

Table 8. 1-Day Compressive Strength Results Irrespective of Moisture Condition

\begin{tabular}{llccc}
\hline $\begin{array}{l}\text { Batching } \\
\text { Group }\end{array}$ & Aggregate Type & $\begin{array}{c}\text { Average } \\
(\mathbf{M P a})\end{array}$ & $\begin{array}{c}\text { Standard } \\
\text { Deviation } \\
(\mathbf{M P a})\end{array}$ & $\begin{array}{c}\text { Range } \\
(\mathbf{\%})\end{array}$ \\
\hline \multirow{2}{*}{ Group 1 } & Natural Sand & 18.5 & 2.8 & 37 \\
& $\begin{array}{l}\text { Manufactured } \\
\text { Sand }\end{array}$ & 19.7 & 4.1 & 56 \\
\hline \multirow{2}{*}{ Group 2 } & Natural Sand & 17.9 & 1.2 & 18 \\
& Manufactured & 19.2 & 1.5 & 22 \\
\hline
\end{tabular}

results in greater mechanical interlock and more surface area for bonding, thereby yielding greater compressive strengths than the natural sand. Similar differences have been noted in the literature based on aggregate type (e.g., [27]-[33]), which has been argued to be resultant from aggregate shape, surface texture, elastic modulus, physical bonding, and/or chemical bonding.

As compressive strength is significantly influenced by the w/cm ratio [34]-[36], it should be expected that changes to the local w/cm ratio, such as due to the aggregate moisture condition in Group 1 batching, should also affect compressive strength. Indeed, Table 9 and Table 10 demonstrate that aggregate moisture condition, regardless of the batching method, did affect the compressive strength. Specifically, the SSD condition yielded the lowest average strength but also the lowest variability, indicating that SSD conditions would be the most reliable for predictable strength. While OD and AD aggregates yielded greater average compressive strengths than SSD, there was also greater variability. The compressive strength trends in Table 9 and Table 10 indicate a rank of increasing strength of: SSD < OD < AD. These trends are also consistent with the literature (e.g., [9]). The comparability of the aggregated Group 1 results in Table 10 are somewhat limited: since the 
aggregate moisture condition was not accounted for in Group 1, both the w/cm and s/c ratios are not equal across mixtures. However, since the Group 2 results did account for aggregate moisture condition, the w/cm and s/c ratios are constant across all mixtures. Regardless, both groups indicate the same rank of increasing strength with SSD aggregates yielding the lowest variability.

\subsection{Discussion of Moisture Content Effects}

As presented in the Introduction, the aggregate moisture condition and how it is accounted for during batching can affect workability, workability loss, strength development, ultimate strength, interfacial transition zone, etc. The primary concern appears to often be sourced from aggregates in an OD condition, and the effects appear to be exasperated as the absorption capacity of the aggregate increases. Indeed, the OD aggregate condition will still absorb moisture, except that the moisture is taken from the hydrating cement paste,

Table 10. 1-Day Compressive Strength Results Irrespective of Aggregate Type

which has been shown to be detrimental to the interfacial transition zone (e.g., [9], [11], [14]), workability loss (e.g., [13], [19]), strength development (e.g., [6], [10], [13]), etc., as it will alter the local w/cm ratio.

Even if the batching water is modified to accommodate the moisture to be absorbed by the aggregate, it is possible that the OD aggregate will not absorb all of the intended moisture before the cementitious matrix sets, which would therefore alter the local w/cm ratio. For instance, Alhozaimy [6] showed that a limestone with around $1.3 \%$ to $1.9 \%$ absorption capacity will only absorb up to $75 \%$ to the added water, leaving the other $25 \%$ as "free" water that will unintentionally increase the $\mathrm{w} / \mathrm{cm}$ ratio. This issue is particularly highlighted as problematic for highly absorptive or heterogeneous aggregates, since it is difficult to actually predict the amount of moisture absorbed by the aggregate during mixing [37]. Furthermore, different aggregate types and size fractions will absorb moisture at different rates [38]. Therefore, based on the findings presented in this study and the potential to unintentionally affect the design w/cm ratio, it is advisable to consider at least partially saturated aggregates for any application where strict quality control of the mortar fresh properties is needed.

\section{Conclusion}

The objective of this study was to evaluate the influence of aggregate moisture condition, aggregate type, and batching methodology between two fine aggregates on the fresh and early age properties of a mortar currently used in additive manufacturing. Specifically, the mortar flow, setting time, and 1-day compressive strength was evaluated for mortars with two aggregate types, with aggregates at three different moisture conditions, and two batching methodologies (e.g., whether or not the aggregate moisture conditions was accounted for). While mortar flow, setting time, and early compressive strength are not the only concerns for mortar fresh properties, they can serve as qualitative indicators as to how different mortars will perform, such as in terms of relative reliability, consistency, and predictability.

In additive manufacturing, control of the fresh properties is very important to ensure that the mixture meets the required timeframe of constructability. Therefore, the fresh properties need to be designed such that the behaviour and performance of the mixture can be predicted and accommodated. This study clearly demonstrated the importance of aggregate type, moisture condition, and absorption capacity and the need to properly account for aggregate moisture during batching. The results demonstrated that the least amount of variability in performance was for aggregates in a saturated surface dry condition. For instance, the setting time standard deviation was decreased by $77 \%$ for aggregate at saturated surface dry vs. oven dry condition, regardless of the batching method. The results also demonstrated that the least amount of variability in performance was for mixtures batched properly to accommodate the aggregate moisture condition and absorption capacity, regardless of the aggregate moisture condition at the time of batching. For example, this was demonstrated by $57 \%$ and $63 \%$ decreases in the standard deviation for 1-day compressive strength for natural sand and manufactured sand fine aggregates, respectively, when the aggregate moisture was accounted for during batching. 
Therefore, based on the data presented, it is recommended that cement mortar or concrete mixtures used in additive manufacturing should design and accommodate the moisture condition of the aggregate to optimise the predictability of the fresh and early-age properties. Moreover, these results are relevant to any construction scenario where mortar fresh properties are important (e.g., grouts for prestressed concrete tendons).

\section{Acknowledgements}

MCJ acknowledges funding from the Via Scholars Program through the Charles E. Via, Jr. Department of Civil and Environmental Engineering at Virginia Polytechnic Institute and State University and from the Institute for Advanced Composites Manufacturing Innovation Summer Internship Program at Oak Ridge National Laboratory.

\section{References}

[1] R. A. Buswell, W. R. Leal De Silva, S. Z. Jones, and J. Dirrenberger, "3D printing using concrete extrusion: A roadmap for research," Cem. Concr. Res., vol. 112, pp. 37-49, 2018.

[2] T. Wangler, N. Roussel, F. P. Bos, T. A. M. Salet, and R. J. Flatt, "Digital concrete: A review," Cem. Concr. Res., vol. 123, p. 105780, 2019.

[3] T. T. Le, S. A. Austin, S. Lim, R. A. Buswell, A. G. F. Gibb, and T. Thorpe, "Mix design and fresh properties for highperformance printing concrete," Mater. Struct., vol. 45, no. 8, pp. 1221-1232, 2012.

[4] D. P. Bentz, S. Z. Jones, I. R. Bentz, and M. A. Peltz, "Towards the formulation of robust and sustainable cementitious binders for 3-D additive construction by extrusion," Constr. Build. Mater., vol. 175, pp. 215-224, 2018.

[5] J. Ortiz, A. Aguado, L. Agulló, T. García, and M. Zermeñoa, "Influence of environmental temperature and moisture content of aggregates on the workability of cement mortar," Constr. Build. Mater., vol. 23, no. 5, pp. 1808-1814, 2009.

[6] A. M. Alhozaimy, "Effect of absorption of limestone aggregates on strength and slump loss of concrete," Cem. Concr. Compos., vol. 31, no. 7, pp. 470-473, 2009.

[7] R. Cortas, E. Rozière, S. Staquet, A. Hamami, A. Loukili, and M.-P. Delplancke-Ogletree, "Effect of the water saturation of aggregates on the shrinkage induced cracking risk of concrete at early age," Cem. Concr. Compos., vol. 50, pp. 1-9, 2014.

[8] C. Gonilho Pereira, J. Castro-Gomes, and L. Pereira de Oliveira, "Influence of natural coarse aggregate size, mineralogy and water content on the permeability of structural concrete," Constr. Build. Mater., vol. 23, no. 2, pp. 602-608, 2009.

[9] A. S. Brand and J. Roesler, "Interfacial transition zone of cement composites with recycled concrete aggregate of different moisture states," Adv. Civ. Eng. Mater., vol. 7, no. 1, pp. 87-102, 2018.

[10] A. S. Brand, J. R. Roesler, and A. Salas, "Initial moisture and mixing effects on higher quality recycled coarse aggregate concrete," Constr. Build. Mater., vol. 79, pp. 83-89, 2015.

[11] M. B. Leite and P. J. M. Monteiro, "Microstructural analysis of recycled concrete using X-ray microtomography," Cem. Concr. Res., vol. 81, pp. 38-48, 2016.

[12] M. Barra de Oliveira and E. Vazquez, "The influence of retained moisture in aggregates from recycling on the properties of new hardened concrete," Waste Manag., vol. 16, no. 1-3, pp. 113-117, 1996.

[13] C. S. Poon, Z. H. Shui, L. Lam, H. Fok, and S. C. Kou, "Influence of moisture states of natural and recycled aggregates on the slump and compressive strength of concrete," Cem. Concr. Res., vol. 34, no. 1, pp. 31-36, 2004.

[14] T. Le, G. Le Saout, E. Garcia-Diaz, D. Betrancourt, and S. Rémond, "Hardened behavior of mortar based on recycled aggregate: Influence of saturation state at macro- and microscopic scales," Constr. Build. Mater., vol. 141, pp. 479490, 2017.

[15] J. García-González, D. Rodríguez-Robles, A. Juan-Valdés, J. M. Morán-del Pozo, and M. I. Guerra-Romero, "Presaturation technique of the recycled aggregates: Solution to the water absorption drawback in the recycled concrete manufacture," Materials, vol. 7, no. 9, pp. 6224-6236, 2014.

[16] D. P. Bentz, I. De la Varga, J. F. Muñoz, R. P. Spragg, B. A. Graybeal, D. S. Hussey, D. L. Jacobson, S. Z. Jones, and J. M. LaManna, "Influence of substrate moisture state and roughness on interface microstructure and bond strength: Slant shear vs. pull-off testing," Cem. Concr. Compos., vol. 87, pp. 63-72, 2018. 
[17] I. De la Varga, J. F. Muñoz, D. P. Bentz, R. P. Spragg, P. E. Stutzman, and B. A. Graybeal, "Grout-concrete interface bond performance: Effect of interface moisture on the tensile bond strength and grout microstructure," Constr. Build. Mater., vol. 170, pp. 747-756, 2018.

[18] Z. Zhao, S. Remond, D. Damidot, and W. Xu, "Influence of fine recycled concrete aggregates on the properties of mortars," Constr. Build. Mater., vol. 81, pp. 179-186, 2015.

[19] H. Mefteh, O. Kebaïli, H. Oucief, L. Berredjem, and N. Arabi, "Influence of moisture conditioning of recycled aggregates on the properties of fresh and hardened concrete," J. Clean. Prod., vol. 54, pp. 282-288, 2013.

[20] P. Chesser, B. Post, A. Roschli, R. Lind, A. Boulger, L. Love, and K. Gaul, "Fieldable platform for large-scale deposition of concrete structures," in 29th Annual International Solid Freeform Fabrication Symposium, 2018.

[21] Y. W. D. Tay, Y. Qian, and M. J. Tan, "Printability region for 3D concrete printing using slump and slump flow test," Compos. Part B Eng., vol. 174, p. 106968, 2019.

[22] D. P. Bentz, M. A. Peltz, and J. Winpigler, "Early-age properties of cement-based materials. II: Influence of water-tocement ratio," J. Mater. Civ. Eng., vol. 21, no. 9, pp. 512-517, 2009.

[23] C.-W. Chung, P. Suraneni, J. S. Popovics, and L. J. Struble, "Setting time measurement using ultrasonic wave reflection," ACI Mater. J., vol. 109, no. 1, pp. 109-118, 2012.

[24] F. Liu, Z. Sun, and C. Qi, "Raman spectroscopy study on the hydration behaviors of portland cement pastes during setting," J. Mater. Civ. Eng., vol. 27, no. 8, p. 04014223, 2015.

[25] D. P. Bentz, "Cement hydration: Building bridges and dams at the microstructure level," Mater. Struct., vol. 40, pp. 397-404, 2007.

[26] A. Kazemian, X. Yuan, R. Meier, and B. Khoshnevis, "Performance-based testing of portland cement concrete for construction-scale 3D printing," in 3D Concrete Printing Technology, J. G. Sanjayan, A. Nazari, and B. Nematollahi, Eds. Butterworth-Heinemann, 2019, pp. 13-35.

[27] D. Bentz, A. Ardani, T. Barrett, S. Jones, D. Lootens, M. Peltz, T. Sato, P. Stutzman, T. Tanesi, and W. Weiss, "Multiscale investigation of the performance of limestone in concrete," Constr. Build. Mater., vol. 75, pp. 1-10, 2015.

[28] T. Özturan and C. Çeçen, "Effect of coarse aggregate type on mechanical properties of concretes with different strengths," Cem. Concr. Res., vol. 27, no. 2, pp. 165-170, 1997.

[29] W. A. Tasong, C. J. Lynsdale, and J. C. Cripps, "Aggregate-cement paste interface: Part I. Influence of aggregate geochemistry," Cem. Concr. Res., vol. 29, no. 7, pp. 1019-1025, 1999.

[30] S. K. Al-Oraimi, R. Taha, and H. F. Hassan, "The effect of the mineralogy of coarse aggregate on the mechanical properties of high-strength concrete," Constr. Build. Mater., vol. 20, no. 7, pp. 499-503, 2006.

[31] C. G. Rocco and M. Elices, "Effect of aggregate shape on the mechanical properties of a simple concrete," Eng. Fract. Mech., vol. 76, no. 2, pp. 286-298, 2009.

[32] D. P. Bentz, J. Arnold, M. J. Boisclair, S. Z. Jones, P. Rothfeld, P. E. Stutzman, J. Tanesi, M. Beyene, H. Kim, J. Muñoz, and A. Ardani, Influence of Aggregate Characteristics on Concrete Performance, NIST Technical Note 1963, National Institute of Standards and Technology, Gaithersburg, MD, 2017.

[33] W. A. Tasong, J. C. Cripps, and C. J. Lynsdale, "Aggregate-cement chemical interactions," Cem. Concr. Res., vol. 28, no. 7, pp. 1037-1048, 1998.

[34] S. Mindess, J. F. Young, and D. Darwin, Concrete, 2nd ed. Prentice Hall, 2003.

[35] P. K. Mehta and P. J. M. Monteiro, Concrete: Microstructure, Properties, and Materials, 4th ed. McGraw-Hill, 2016.

[36] A. M. Neville, Properties of Concrete, 5th ed. Upper Saddle River: Prentice Hall, 2012.

[37] M. Joseph, L. Boehme, Z. Sierens, and L. Vandewalle, "Water absorption variability of recycled concrete aggregates," Mag. Concr. Res., vol. 67, no. 11, pp. 592-597, 2015.

[38] V. Ayan, J. R. Omer, M. C. Limbachiya, and S. M. N. Azadani, "Water absorption and frost heaving of recycled aggregates," Proc. Inst. Civ. Eng. - Constr. Mater., vol. 166, no. 3, pp. 127-132, 2013. 